\title{
Complicación asociada a la enfermedad celíaca
}

\author{
R. BAÑOS MADRID, J. MERCADER MARTÍNEZ, F. SÁNCHEZ BUENO*, A. BAS \\ BERNAL** \\ Servicio de Medicina del Aparato Digestivo, *Cirugía General y **Anatomía Patológica. \\ Hospital Universitario Virgen de la Arrixaca. Murcia
}

\author{
CELIAC DISEASE ASSOCIATED COMPLICATION
}

\section{RESUMEN}

El linfoma de células T es la complicación más grave asociada a la enfermedad celíaca. La incidencia de cáncer es aproximadamente el doble en pacientes celíacos en comparación con la población general, siendo el riesgo de cánceres gastrointestinales marcadamente mayor. El Linfoma de intestino delgado supone el $50 \%$ y la mayoría derivan de los linfocitos T intraepiteliales. Presentamos el caso de una enferma celíaca con linfoma $\mathrm{T}$ de yeyuno. A la edad de 33 años fue diagnosticada de celiaquía, después de la introducción de una dieta sin gluten la paciente mejora, pero quince años más tarde presenta un cuadro de fiebre y dolor abdominal. La laparotomía demuestra la perforación del intestino por una tumoración.

PALABRAS CLAVE: Linfoma de células T. Enfermedad celíaca.

\begin{abstract}
Enteropathy associated T cell lymphoma is the most serious compli cation of celiac sprue. The incidence of malignancy, in general, is appro ximately twofold greater in celiac disease than in the general population, but the risk of specific gastrointestinal malignancies is markedly increa sed. Lymphoma of the small intestine, comprises approximately $50 \%$ of the malignancies, and the most are of T-cell origin. We report a case of celiac disease associated T-cell Lymphoma of the jejunum in a woman. At the age of 33 the diagnosis of Celiac sprue was made, after institucion of a gluten free diet the patient improved, but, fifteen year later, the patient begin with fever and abdominal pain. Laparotomy showed a per foration of the intestine by a tumour.
\end{abstract}

KEY WORDS: T-cell Lymphoma. Celiac disease.

Baños Madrid R, Mercader Martínez J, Sanchez Bueno F, Bas Bernal A. Complicación asociada a la enfermedad celíaca. An Med Interna (Madrid) 2002; 19: 81-84.

\section{INTRODUCCIÓN}

La enfermedad celíaca se ha caracterizado históricamente por la atrofia de las vellosidades intestinales, malabsorción de nutrientes y la mejoría clínica e histológica tras la retirada del gluten de la dieta. Desgraciadamente esta visión tan simplista, no puede ser aceptada actualmente, tras el conocimiento de que la enfermedad celíaca puede presentarse con un único síntoma digestivo o extradigestivo, de forma silente, o en individuos genéticamente predispuestos a presentar hiperreactividad al gluten, que pueden permanecer asintomáticos siempre que ésta no sea desenmascarada por factores ambientales tales como infecciones o malignidad (1).

La tasa de mortalidad del paciente celíaco está incrementada en relación con la población general debido a las neoplasias. Las neoplasias cuya frecuencia está incrementada en la enfermedad celíaca son, en primer lugar el linfoma $\mathrm{T}$ intestinal y en segundo lugar el adenocarcinoma de intestino delgado y los carcinomas del tercio superior del esófago y faringe (2).
A continuación presentamos una paciente con enfermedad celíaca y diagnóstico de Linfoma T perforado en yeyuno.

\section{CASO APORTADO}

Mujer de 48 años, ingresada en nuestro servicio, quince años antes, por diarrea y vómitos de quince días de evolución, con adelgazamiento de diez kilogramos durante este período. Refería episodios similares aunque menos importantes desde niña, en la analítica de este ingreso, destacaba una GPT/GOT moderadamente elevada y en la biopsia yeyunal se observó una atrofia vellositaria subtotal con hiperplasia de criptas e infiltración inflamatoria de predominio crónico en el corion. Es dada de alta con el diagnostico de enfermedad celíaca tras desaparecer la sintomatología con una dieta exenta de gluten, desde entonces estaba en tratamiento con dieta sin gluten, que según afirmaba la paciente la realizaba de una forma estricta. Ingresa en un centro hospitalario por fiebre de un mes de evolución y dolor continuo en vacío izquierdo, acompañado de anorexia y pérdida de unos $6 \mathrm{Kg}$ de peso. Con la sospecha ecográfica de absceso intraabdominal es remitida a nuestro hospital.

Trabajo aceptado: 11 de Julio de 2000

Correspondencia: Ramón Baños Madrid. C/ Alameda de San Antón, 38-1º B. 30205 Cartagena. Murcia. 
A la exploración destaca: $\mathrm{T}^{\mathrm{a}} 37,3^{\circ}$, desnutrición ligera, palidez cutánea, no adenopatías periféricas. Auscultación cardiorrespiratoria normal. En la exploración abdominal, se aprecia a la palpación profunda una masa redondeada y dolorosa en vacío izquierdo de unos 6 cm de diámetro. Analítica: Anemia normocítica - normocrómica leve, 6,6 leucocitos x 10\%/l (Neutrófilos 71,1\%-), 530 plaquetas x $10 \%$, proteínas totales $6 \mathrm{gr} / \mathrm{dl}$, albúmina $3 \mathrm{gr} / \mathrm{dl}$, Inmunoquímica (Ig M sérica $44 \mathrm{mg} / \mathrm{dl}$, resto dentro de la normalidad), GPT $144 \mathrm{U} / \mathrm{L}$, GOT 154 U/L. Hemocultivos seriados y Urocultivo negativos. Anticuerpos no organoespecíficos: Antireticulina positivo, Antigliadina Ig G 32 UR/ml (VN <33), Antigliadina Ig A 15 UR/ ml (VN<43), resto negativos.

Se practica una Gastroscopia en la que se evidencia una mucosa duodenal lisa, con patrón en mosaico de la mucosa de duodeno y yeyuno proximal. En el transito intestinal se visualiza una perforación a nivel del intestino delgado (Fig.1). En la TAC Abdominal se aprecia la perforación del intestino delgado dependiente de asas yeyunales, compatible con tumoración, sin imágenes de adenopatías (Fig.2). En el estudio de extensión realizado (TAC torácico, gammagrafía ósea y punción de la médula ósea, no se evidenciaba afectación extraintestinal).

A la vista de las imágenes radiológicas y con la sospecha de tumoración abdominal es intervenida. Intraoperatoriamente se evi-
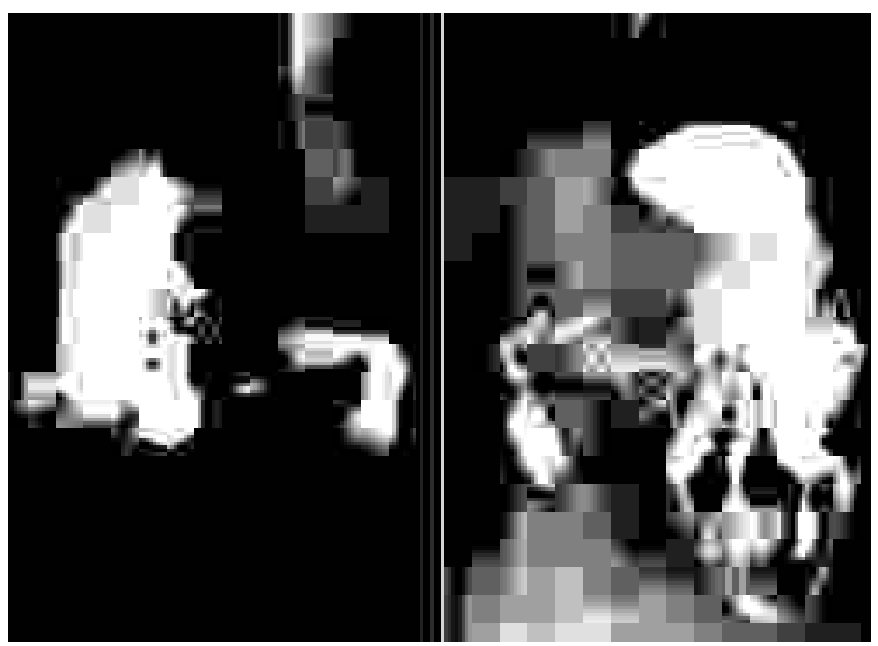

Fig. 1. Transito intestinal donde se distingue la perforación (flecha) de la tumoración a nivel de un asa de intestino delgado.

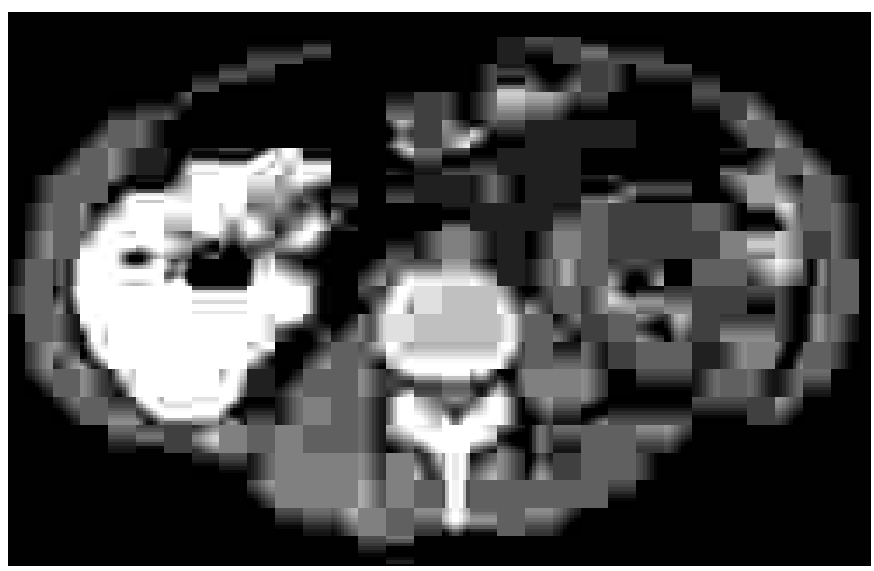

Fig. 2. TAC abdominal donde se visualiza la perforación de intestino delgado, a nivel de un asa yeyunal, con edema perilesional, marcado engrosamiento de la pared e irregularidad de la mucosa. dencia tumor abdominal de intestino delgado localizado en un asa yeyunal, que engloba un par de asas y se perfora en ellas, el resto de intestino delgado, grueso, estómago e hígado no evidenciaron alteraciones. Se realiza resección intestinal con reconstrucción terminoterminal.

En el estudio microscópico de la pieza quirúrgica se objetivó la presencia de una neoplasia maligna de naturaleza linfoide de alto grado de malignidad, constituida por elementos de tamaño grande o intermedio con núcleos vesiculosos prominentes. El fenotipo de las células tumorales era CD3 (+), CD 20 (-), CD 30 (-), antígeno de proliferación Ki 67 (70\%), cadenas Kappa (-) y Lambda (+), positivas probablemente por absorción pasiva. En las porciones adyacentes a la tumoración, la mucosa muestra intensa atrofia vellositaria, con hiperplasia críptica y linfocitos intraepiteliales pequeños. El postoperatorio transcurrió sin complicaciones, por lo que la paciente es dada de alta con el diagnostico de Linfoma $\mathrm{T}$ asociado a enteropatía. La enferma recibe posteriormente seis ciclos de quimioterapia postoperatoria ,mediante esquema CHOP ( ciclofosfamida + doxorubicina + vincristina + prednisona). Seis meses después de terminar el tratamiento con quimioterapia, la paciente ingresa de nuevo por fiebre y deterioro del estado general, falleciendo a los quince días.

\section{DISCUSIÓN}

La asociación entre la enfermedad celíaca y distintas formas de malignidad ha sido ampliamente estudiada. Los datos disponibles en la actualidad indican que, en comparación con la población general, los pacientes con enfermedad celíaca tienen un riesgo relativo (RR) de 2 para el cáncer en general. Alrededor del $15 \%$ de los celíacos padecen algún tipo de neoplasia, el $50 \%$ de los casos son linfomas de origen celular T localizados en el tracto gastrointestinal $(3,4)$.

Los pacientes celíacos con linfoma suelen presentar la enfermedad de una de las maneras siguientes:

1.Responde de manera favorable al tratamiento con dieta exenta de gluten, pero más tarde se deteriora clínicamente por el linfoma.

2.Presenta enfermedad celíaca y malignidad al mismo tiempo.

3.La enfermedad aparece de forma aguda, con perforación, obstrucción o hemorragia intestinal.

4.En muchos casos de linfoma asociado a enfermedad celíaca, no hay historia previa de malabsorción o evidencia biopsica de sensibilidad al gluten y además la mucosa yeyunal resecada es normal (5).

Lo anterior podría explicarse aplicando el concepto de latencia, en la que la mucosa yeyunal puede ser normal histológicamente y no tener sintomatología, pero si estar presentes determinados anticuerpos o marcadores HLA, que también nos encontramos en la enfermedad celíaca clásica, esta normalidad histológica en un momento dado no excluye la expresión posterior de enfermedad celíaca (6).

Dentro del grupo de anticuerpos que nos sirven de ayuda para el diagnostico de enfermedad celíaca están los Ig A e Ig G Antigliadina, Ig A Antirreticulina (R1), Ig A Antiendomisio (mayor sensibilidad y especificidad), otro marcador que podrá utilizarse en un futuro es el autoantígeno reconocido por la Ig A Antiendomisio, llamado Transglutaminasa del tejido (TGt) (7). Hay que tener en cuenta que hay un $2 \%$ de celíacos con deficiencia de Ig A, en estos casos no nos servirán los Anticuerpos Ig A. En más del $95 \%$ de los enfermos con enfermedad celíaca sintomática o latente y en la compli- 
cada con linfoma está presente el HLA DQA $1 * 0501$ y el HLADQB $1 * 0201$. Otros marcadores HLA-DR/DQ estarían asociados con la aparición de la enfermedad celíaca del adulto, lo cual representa un factor de riesgo adicional para el desarrollo del linfoma (8). El gen CTLA-4 también estaría asociado con una mayor predisposición a padecer la enfermedad celíaca (9).

Los mecanismos responsables de la alta malignidad asociada a la enfermedad celíaca, no son conocidos. Se han sugerido determinados factores que solos o en combinación intervienen; una actividad mitótica críptica aumentada, aumento del recambio de células linfoides dentro de la mucosa, penetración a nivel de la mucosa yeyunal dañada de carcinógenos, infecciones por virus oncogénicos, anormalidades del sistema inmune de la mucosa, así como la continua estimulación inmune por la gliadina, podrían favorecer la progresión a linfoma (10).

Una de las teorías que intenta explicar el alto riesgo de malignidad asociado a la enfermedad celíaca considera, que los pacientes celíacos, presentan una permeabilidad intestinal incrementada que permite la absorción de determinados peptidos con actividad opiode, que derivan del gluten. La presencia en el torrente sanguíneo de estos peptidos incrementa el riesgo de linfomas al alterar el eje hipotálamohipofisiario-adrenal y disminuir la producción de células Natural-Killer (11)

Algunos autores han sugerido que una dieta estricta sin gluten podría ser un factor de protección contra el desarrollo de malignidad. Se apoyan en el hecho de que la mucosa intestinal de la enfermedad celíaca no tratada presenta una permeabilidad elevada, por lo que es posible que la penetración de carcinógenos a su través también lo esté. La dieta exenta de gluten restituye la estructura y la función de la mucosa intestinal de los pacientes celíacos, por lo que resulta lógico pensar que pueda disminuir el riesgo de malignidad de los pacientes. Uno de los estudios que investiga estos aspectos, y para el que se siguió a un importante número de pacientes celíacos, durante muchos años, afirma que en aquellos pacientes que siguieron una dieta exenta de gluten durante más de 5 años se encontró un riesgo de malignidad bajo ( $R R=6,7)$, en comparación con el de los pacientes que consumían gluten $(\mathrm{RR}=38,7)(12)$, otros estudios posteriores apoyan estos resultados, aunque ninguno es concluyente (13). La ausencia de estudios en contra de esta protección, con suficiente muestra y con seguimiento a largo plazo, constituye una razón adicional para ser prudentes y aconsejar a los celíacos que sigan una dieta exenta de gluten.

Los pacientes afectados con linfoma intestinal se hallan en la quinta-sexta década de la vida, las series publicadas muestran una preponderancia del sexo masculino $(3,3 / 1)$ para los linfomas T. En la mayoría de estas series, la presentación clínica consiste en dolor abdominal, sensación de plenitud, anorexia y perdida de peso. La perforación tumoral se presenta en la mitad de los linfomas T intervenidos quirúrgicamente. La localización más frecuente es en yeyuno.

Los datos bioquímicos descritos son los asociados a malabsorción, y en el estudio hematológico puede haber leucocitosis, y eosinofília. La neutrofília esta asociada a perforación intestinal. En un tercio de los pacientes hay anemia y trombocitosis. En nuestra paciente destacaba una elevación persistente GOT/GPT, desde su diagnostico. Esta elevación de las transaminasas es un hecho frecuentemente observado en los pacientes celíacos, en los que se ha observado una alta incidencia de hepatopatía crónica, mayor que la esperada en la población general, lo que permite sugerir una asociación real entre la enfermedad celíaca y la enfermedad hepática.

Los linfomas $\mathrm{T}$ intestinales son principalmente placas aisladas, ulceradas o estenosantes con importante edema y congestión, señal de los cambios isquémicos que se producen a nivel de mucosa y pared intestinal. Las células tumorales se localizan preferentemente en la lámina propia, mientras que las estructuras epiteliales y otras capas no están envueltas por la proliferación tumoral. En la mayoría de los linfomas $\mathrm{T}$ independientemente del tipo tumoral, la mucosa adyacente a la masa tumoral contiene abundantes acúmulos de células $\mathrm{T}$ intraepiteliales. El tipo histológico más frecuente está compuesto por células blásticas medianas y grandes, con citoplasma moderadamente abundante y núcleo vesicular con nucleolo eosinofílico prominente. La siembra microscópica tumoral puede existir en otras localizaciones incluyendo hígado, bazo y médula ósea. La mayoría de los linfomas $\mathrm{T}$ son de alto grado de malignidad. En los linfomas $\mathrm{T}$ de intestino existen dos tipos de linfocitos $\mathrm{T}$, los linfocitos $\mathrm{T}$ intraepiteliales y las células $\mathrm{T}$ tumorales que derivan de las primeras, según queda manifiesto con métodos inmunohistoquímicos. El fenotipo CD3+, CD4-, CD8+, CD103+ es característico de las células T tumorales, y también está presente en las células T intraepiteliales 14 . Otro marcador inmunohistoquímico que parece ser específico de las células $\mathrm{T}$ del intestino es el antígeno identificado por el anticuerpo monoclonal HML1.La positividad para los anticuerpos monoclonales contra los linfocitos $\mathrm{T}$ de la mucosa humana (HML1) es característica de los linfomas T. La expresión del antígeno HML1 en las células tumorales es la evidencia de que tiene su origen en los linfocitos intraepiteliales (15).

El diagnostico del linfoma intestinal es difícil, sólo la sospecha clínica nos podrá llevar al diagnostico. Sus síntomas son vagos, y es imprescindible para su diagnostico un buen examen radiológico. La enteroclisis se ha demostrado que es un método muy sensible para el diagnostico, y es el procedimiento de elección para detectar anormalidades y localizar pequeñas lesiones de intestino delgado. La enteroscopia es una técnica que jugará un importante papel en el diagnostico de los tumores de intestino delgado en el futuro, sin embargo en la actualidad hay limitaciones de índole técnico. La laparotomía es fundamental para el diagnostico, el estadiaje tumoral y la toma de muestras para anatomía patológica.

El pronóstico de los linfomas T es malo, con una supervivencia a los cinco años del $25 \%$, siendo los factores pronósticos a valorar numerosos, los más significativos son la presencia de masa abdominal palpable, tamaño del tumor, grado histológico, estadio del tumor y tipo de cirugía realizada, curativa o paliativa (16). La única posibilidad de una temprana curación es la resección precoz. El tratamiento de elección es la resección quirúrgica radical y posteriormente quimioterapia adyuvante (17). 


\section{Bibliografía}

1. Marsh MN. Gluten sensitivity and latency: can patterns of intestinal antibody secretion define the great "silent majority"? (Editorial): Gastroenterology 1993; 104: 1550-1553.

2. Madriano Cobo O, Lorenzo Hernández A, Fernández Capitán C, Arnalich Fernández F, Vázquez Rodríguez JJ. Enfermedad celíaca del adulto. An Med Interna (Madrid) 1998; 15: 327-333.

3. Remacha B, Palau A, Velicia R, Caro-Patón A, Ripollés V. Linfoma T primario intestinal. Rev Esp Enferm Dig 1998; 90 (3): 183-190.

4. Ghott A, Dragosics B, Radaszkiewicz T. Peripheral T- Cell Lymphomas of the intestine. Am J Pathol 1992; 141: 1361-1371.

5. McCarthy CF. Malignancy in coeliac disease. Eur J Gastroenterol Hepatol 1991; 3: 125-128.

6. Troncone R. Latent coeliac disease in Italy. SIGEP Working Group on Latent Coeliac Disease. Acta Pediat 1995; 84 (11): 1252-1257.

7. Trier JS. Diagnosis of celiac sprue. Gastroenterology 1998; 115: 211-6.

8. Wright DH. Enteropathy associated T cell Lymphoma. Cancer Surv 1997; 30: 249-261.

9. Djilali-Saiah 1, Schmitz J, Harfouch-Hammoud E, Mougenot JF, Bach J F, Caillat-Zucman S. CTLA-4 gene polymorphism is associated with predisposition to coeliac disease. Gut 1998; 43: 187-189.

10. Kagnoff MF. Celiac disease. En: Yamada T, Alpers DH, Owyang C, Powell DW, Silverstein FE editores. Textbook of Gastroenterology (2. ${ }^{a}$ ed). Filadelfia: JB Lippincott Company, 1995; 1643-1656.
11. Hoggan R. Considering wheat, rye, and barley proteins as aids to carcinogens. Med Hypotheses 1997; 49(3): 285-288

12. Holmes GKT, Prior P, Lane MR, Pope D, Allan RN. Malignancy in coeliac disease-effect of a gluten free diet. Gut 1989; 30: 333-338.

13. Auricchio S. Effects of small amounts of gluten in the diet of coeliac disease. Panminerva Med 1991; 33: 83-85.

14. Schmitt-Graff, Daum S, Hummel M, Zemlin M, Stein H, Riecken EO. Presence of clonal $\mathrm{T}$-cell receptor gene rearrangements provides evidence of widespread intramucosal intestinal T-cell lymphoma. Gastroenterol 1996; 34 (10): 680-685.

15. Spencer J, Cerf-Bensussan N, Jarry A, Brousse N, Guy-Grand D, Krajewski AS, Isaacson PG. Enteropathy-associated T cell lymphoma (malignant histiocytosis of the intestine) is recognized by a monoclonal antibody (HML-1) that defines a membrane molecule on human mucosal lymphocytes. Am J Pathol 1988; 132: 1-5.

16. Sanchez F, García J A, Alonso JD, Acosta J ,Carrasco L, Piñero A, Parrilla P. Prognostic factors in primary gastrointestinal non- Hodgkin's lymphoma: a multivariate analysis of 76 cases. Eur J Surg 1998; 164: 385-392.

17. Egan LJ, Walsh SV, Stevens FM, Connolly CE, Egan EL, McCarthy C F. Celiac associated lymphoma. A single institution experience of 30 cases in the combination chemotherapy era. J Clin Gastroenterol 1995; 21 (2): 123-129. 